Article

\title{
Physalis angulata Calyces Modulate Macrophage Polarization and Alleviate Chemically Induced Intestinal Inflammation in Mice
}

\author{
David Rivera ${ }^{\mathbb{D}}$, Yanet Ocampo ${ }^{\mathbb{D}}$ and Luis A. Franco *(D) \\ Biological Evaluation of Promising Substances Group, Department of Pharmaceutical Sciences, \\ University of Cartagena, Carrera 50 No. 29-11, Cartagena 130014, Colombia; \\ driveram@unicartagena.edu.co (D.R.); yocampob@unicartagena.edu.co (Y.O.) \\ * Correspondence: lfrancoo@unicartagena.edu.co
}

Received: 26 December 2019; Accepted: 3 February 2020; Published: 5 February 2020

\begin{abstract}
As part of the search for new bioactive plants from the Colombian Caribbean, the dichloromethane fraction of the calyces of Physalis angulata L. (PADF) was selected for its anti-inflammatory activity. In this work, we investigated the immunomodulatory effect of PADF in activated macrophages and during dextran sulfate sodium (DSS)-induced colitis. PADF displayed a low content of withanolides or phenolic compounds, and a higher content of sucrose esters, representative anti-inflammatory metabolites of the Physalis genus. The PADF fraction at 12.5 $\mu \mathrm{g} / \mathrm{mL}$ prevented the induction of interleukin (IL)- $1 \beta$, tumor necrosis factor (TNF- $\alpha$ ), IL-6, IL-12, cyclooxygenase-2 (COX-2), and inducible nitric oxide synthase (iNOS) by lipopolysaccharide (LPS), while increased the levels of arginase (ARG1), IL-10, and mannose receptor C (MRC1). The polarization towards an anti-inflammatory profile was also observed in resting macrophages, without promoting the typical gene profile induced by IL-4, suggesting that PADF promotes a shift to a regulatory status rather than to an alternative one. In vivo, the administration of PADF to mice with chronic DSS-colitis reduced disease signs (i.e., body weight loss and colon shortening), and improved the histology score by diminishing the levels of pro-inflammatory cytokines and increasing the production of IL-10. Overall, results suggest that the regulatory effect on PADF towards macrophages might contribute to the therapeutic activity observed in the murine model of inflammatory bowel disease.
\end{abstract}

Keywords: Physalis angulata; macrophages; inflammatory bowel disease

\section{Introduction}

The discovery of novel bioactive compounds from medicinal plants and animals continues to be an interesting/attractive strategy for the development of new drugs with a unique chemical and pharmacological profile; in fact, a new golden era for natural product research is anticipated from the recent technological advances and the current attention to naturally-derived drugs motivated by the 2015 Nobel Prize in Physiology or Medicine awarded to William C. Campbell, Satoshi Omura, and Youyou Tu for the discovery of avermectins and artemisinin, respectively [1].

Certainly, herbal medicines and metabolites have a high potential to treat a wide spectrum of diseases, and are used not only in developing countries, where up to $80 \%$ of the population still depends on traditional medicine and medicinal herbs for primary health care, but also in developed countries, where the influence of natural products in the pharmaceutical industry is remarkable [2,3]. Colombia, having one of the largest and complex biodiversity, has enormous potential to generate scientific knowledge to establish an innovative, sustainable, and profitable local industry for natural health products. The Physalis genus (Solanaceae), which includes 90 species native to America, constitutes 
an excellent exemplification of the exploitation of endemic plants to develop valuable commercial products. Recently, increasing attention on the phytochemistry and pharmacological effect of Physalis has led to the development of commercial formulations, varying from functional foods and cosmetics to health products [4]. This has been accomplished with species cultivated on a large scale (i.e., Physalis peruviana and Physalis alkekengi) [5,6], but progress is limited with those growing wildly or cultivated at small scale. Our ongoing bioprospecting investigation on the Colombian Caribbean led to the identification of the anti-inflammatory potential of the calyces of Physalis angulata L. [7]; a wild species with extensive cultivation potential in tropical areas [8]. Although P. angulata is already recognized as a model of wide interest for its pharmacological and nutritional properties [9], few studies have focused on the calyces, a characteristic organ of the Physalis genus that is developed after pollination by modified leaves, forming a papery lantern-like structure that covers and protects the fruit [10]. Given their physiological role, calyces are supposed to constitute a prolific reservoir of bioactive metabolites, in comparison with the rest of the plant. Focusing on the anti-inflammatory potential of P. angulata, numerous studies have demonstrated strong immunomodulatory function of several derivatives, with recent reports revealing the immunosuppressive effects of some withanolides due to regulation of macrophage polarization [11].

This work describes a pharmacological study of the dichloromethane fraction from P. angulata calyces, including the assessment of its immunomodulatory effect in activated macrophages, and mice with chemically induced intestinal inflammation.

\section{Experimental Section}

\subsection{Reagents and Chemicals}

Solvents, Dulbecco's Modified Eagle Medium (DMEM), Roswell Park Memorial Institute medium (RPMI), antibiotics (penicillin/streptomycin), lipopolysaccharide (LPS) from Escherichia coli 0127:B8, O-dianisidine, and hematoxylin-eosin (H\&E) were purchased from Sigma-Aldrich (St. Louis, MO, USA). Fetal Bovine Serum (FBS) was acquired from Gibco (Sao Paulo, Brazil). Recombinant mouse interleukin (IL)-4 was obtained from MACS/Miltenyi Biotec (Bergisch Gladbach, Germany). Dextran sulfate sodium (DSS; MW 36-50 kDa) was purchased from MP Biomedicals (Santa Ana, California, USA). Hexadecyltrimethylammonium (HTAB) and hydrogen peroxide $\left(\mathrm{H}_{2} \mathrm{O}_{2}\right)$ were obtained from Calbiochem ${ }^{\circledR}$ (San Diego, CA, USA).

\subsection{Plant Collection and Preparation of the Dichloromethane Fraction from P. angulata}

The calyces of Physalis angulata L were collected at Pueblo Nuevo, Bolívar, Colombia $\left(10^{\circ} 44^{\prime} \mathrm{N}\right.$; $75^{\circ} 15^{\prime} \mathrm{W}$ ) and identified by Felipe Cardona Naranjo in the herbarium of the University of Antioquia (Medellin, Colombia), where a voucher specimen was deposited (HUA175328). Dried calyces were employed to obtain the dichloromethane fraction (PADF) as previously reported by Rivera et al. [7] and fully described in the Supplementary Information.

\subsection{Cell Culture}

The RAW 264.7 macrophage cell line (TIB-71 ${ }^{\mathrm{TM}}$ ) was obtained from the American Type Culture Collection (ATCC; Manassas, VA, USA) and maintained in DMEM with $10 \% \mathrm{FBS}$ at $37^{\circ} \mathrm{C}$ and $5 \% \mathrm{CO}_{2}$.

\subsection{Macrophage Activation and Gene Expression}

RAW 264.7 macrophages (750,000 cells/well) were seeded in 6-well plates for $48 \mathrm{~h}$, then treated with PADF (0-12.5 $\mu \mathrm{g} / \mathrm{mL})$ for $1 \mathrm{~h}$, and stimulated with LPS $(1 \mu \mathrm{g} / \mathrm{mL})$ or IL-4 $(40 \mathrm{ng} / \mathrm{mL})$ to induce an inflammatory M(LPS) or an alternative M(IL4) profile, respectively. Six hours after stimulation, RNA was extracted using the RNeasy Mini Kit from Qiagen (Valencia, CA, USA) and the cDNA was synthetized with the Transcriptor Universal cDNA Master (Roche, Mannheim, Germany). Subsequently, the cDNA was used to assess changes in gene expression (IL-1 $\beta$, tumor necrosis factor (TNF- $\alpha$ ), IL-6, 
IL-12, cyclooxygenase-2 (COX-2), inducible nitric oxide synthase (iNOS), arginase (ARG1), IL-10, transforming growth factor, beta 1 (TGF- $\beta 1$ ), and mannose receptor $C$ (MRC1) using a LightCycler 96 and the Fast Start Essential DNA Green Master (Roche, Mannheim, Germany). Specific primers (Eurofins Genomics, Huntsville, USA) sequences are listed in Table 1. Gene expression was normalized to $\beta$-actin, using duplicate cycle threshold $(\mathrm{CT})$ values analyzed by the comparative $\mathrm{CT}(\triangle \Delta \mathrm{CT})$ method.

Table 1. Sequences of Primers used for Real-time PCR analysis.

\begin{tabular}{|c|c|c|}
\hline Gene Symbol & Official Name & Primer Sequence $^{1}$ \\
\hline $\begin{array}{c}\text { ACTB } \\
(\beta \text {-actin })\end{array}$ & Actin, beta & $\begin{array}{l}\text { F: TAGGCGGACTGTTACTGAGC } \\
\text { R: TGCTCCAACCAACTGCTGTC }\end{array}$ \\
\hline ARG1 & Arginase & $\begin{array}{l}\text { F: TCGTGTACATTGGCTTGCGA } \\
\text { R: GCCAATCCCCAGCTTGTCTA }\end{array}$ \\
\hline $\begin{array}{l}\text { PTGS2 } \\
(\mathrm{COX}-2)\end{array}$ & $\begin{array}{c}\text { Prostaglandin endoperoxide } \\
\text { synthase } 2\end{array}$ & $\begin{array}{l}\text { F: TTCAACACACTCTATCACTGGC } \\
\text { R: AGAAGCGTTTGCGGTACTCAT }\end{array}$ \\
\hline IL-1 $\beta$ & Interleukin 1 beta & $\begin{array}{l}\text { F: CTTCCTTGTGCAAGTGTCTG } \\
\text { R: GCCTGAAGCTCTTGTTGATG }\end{array}$ \\
\hline IL-6 & Interleukin 6 & $\begin{array}{l}\text { F: CTGCAAGAGACTTCCATCCAG } \\
\text { R: AGTGGTATAGACAGGTCTGTTGG }\end{array}$ \\
\hline IL-10 & Interleukin 10 & $\begin{array}{l}\text { F: TGCCTGCTCTTACTGACTGG } \\
\text { R: CTGGGAAGTGGGTGCAGTTA }\end{array}$ \\
\hline IL-12 & Interleukin 12 & $\begin{array}{l}\text { F: TGGTTTGCCATCGTTTTGCTG } \\
\text { R: ACAGGTGAGGTTCACTGTTTCT }\end{array}$ \\
\hline iNOS & Nitric oxide synthase 2 , inducible & $\begin{array}{l}\text { F: ACATCGACCCGTCCACAGTAT } \\
\text { R: CAGAGGGGTAGGCTTGTCTC }\end{array}$ \\
\hline MRC1 & Mannose receptor, $\mathrm{C}$ type 1 & $\begin{array}{l}\text { F: GCTTCCGTCACCCTGTATGC } \\
\text { R: TCATCCGTGGTTCCATAGACC }\end{array}$ \\
\hline TGF- $\beta 1$ & Transforming growth factor, beta 1 & $\begin{array}{l}\text { F: ACTGGAGTTGTACGGCAGTG } \\
\text { R: TCATGTCATGGATGGTGCCC }\end{array}$ \\
\hline $\begin{array}{c}\text { TNF } \\
(\text { TNF- } \alpha)\end{array}$ & Tumor necrosis factor & $\begin{array}{l}\text { F: ACCCTCACACTCAGATCATC } \\
\text { R: GAGTAGACAAGGTACAACCC }\end{array}$ \\
\hline
\end{tabular}

\subsection{Animals}

Four-week-old female CD-1(ICR) mice were obtained from the Instituto Nacional de Salud (Bogotá, Colombia). Animals were housed in filtered-capped polycarbonate cages and kept in a controlled environment $\left(22 \pm 3{ }^{\circ} \mathrm{C}, 65-75 \%\right.$ humidity, under a $12 \mathrm{~h}$ light/darkness cycle) with access to food and water ad libitum. All the experiments were designed and conducted in accordance with local and international regulations (EU Directive 2010/63/EU) and approved by the Committee of Ethics in Research of the University of Cartagena (Project Approval No 81 from 13 August 2015).

\subsection{DSS-Induced Colitis Model}

Animals were randomized into control (vehicle), colitis-control (DSS group), and treatment groups $(n=6-17)$. Colitis was induced with $4 \%(w / v)$ DSS in drinking water during two seven-day cycles, separated by ten days of regular water. Two doses of PADF ( 5 and $10 \mathrm{mg} / \mathrm{Kg}$ ) were administered intraperitoneally (i.p.) during seven days after DSS withdrawal, while the control group was treated with saline. Body weight and disease activity index (DAI) were monitored exhaustively [12]. Macroscopic parameters, such as colon length and weight/length ratio were also measured after mice sacrifice. 


\subsection{Histologic Analysis}

Colonic tissue samples were preserved in buffered formalin and embedded in paraffin, $5 \mu \mathrm{m}$ sections were cut and stained with H\&E. Damage to the epithelial structure and cell infiltration in the colonic tissue were qualified using a 0 to 4 score (0: none, 1: mild, 2: moderate, 3 : high and 4: very high) by a blind pathologist using light microscopy (Axio Lab A1, Zeiss, Oberkochen, Germany).

\subsection{Myeloperoxidase (MPO) Activity Assessment}

MPO activity was measured according to the method described by Bradley et al. [13]. Colonic tissue samples were homogenized using a potassium phosphate buffer containing $0.5 \% \mathrm{HTAB}$, subjected to three freezing/thawing cycles in liquid N2, and finally centrifuged to obtain a supernatant used to determine MPO levels with $\mathrm{O}$-dianisidine, $\mathrm{HTAB}$, and $\mathrm{H}_{2} \mathrm{O}_{2}$. MPO activity was expressed as enzyme activity units per mg of protein. Protein concentration was measured using the Bradford assay (Bio-Rad, Laboratories Inc., Hercules, CA, USA).

\subsection{Determination of Pro-Inflammatory Cytokines in Colon and Mesenteric Lymph Nodes}

On one hand, colonic tissue was subjected to mechanical homogenization and centrifugation in Tissue Protein Extraction Reagent (T-PER, Thermo Fisher Scientific, Waltham, Massachusetts, USA), supplemented with complete protease inhibitor cocktail (Roche). The levels of IL-1 $\beta$, IL-6, IL-10, and TNF- $\alpha$ were determined by ELISA (Thermo Fisher Scientific, Waltham, MA, USA) and normalized to total protein, as measured by Bradford assay (Bio-Rad). On the other hand, mesenteric lymph nodes (MLN) from healthy mice $(n=3)$ were used to obtain a single cell suspension that was cultured in 24-well plates $\left(1 \times 10^{6}\right.$ cells/well) using RPMI-1640 medium, supplemented with $10 \%$ FBS and antibiotics, at $37{ }^{\circ} \mathrm{C}$ and $5 \% \mathrm{CO}$. After $1 \mathrm{~h}$, the cells were treated with PADF $(12.5 \mu \mathrm{g} / \mathrm{mL})$ for an additional hour and then stimulated with LPS $(1 \mu \mathrm{g} / \mathrm{mL})$ for $24 \mathrm{~h}$. Finally, the supernatants were collected to determine IL- 6 and MCP-1 levels by ELISA (Thermo Fisher Scientific).

\subsection{Statistical Analysis}

Results are expressed as the mean \pm standard error of the mean (SEM) of at least two independent experiments. Data were analyzed using one-way analysis of variance (ANOVA), followed by Dunnett's post hoc test. Values of $p<0.05$ were considered significant.

\section{Results}

\subsection{Extraction of P. angulata and Preliminary Phytochemical Study of PADF}

A total of $6.32 \mathrm{~g}$ of the dichloromethane fraction (PADF) were obtained from $234 \mathrm{~g}$ of dried calyces ( $2.70 \%$ yield) from P. angulata. The phytochemical characterization of F0-2 was performed by HPLC-DAD to generate a reliable chemical fingerprint to control the quality of future preparations and to predict bioactivity, as described in the Supplementary Information. However, the identity of the characteristic peaks of F0-2 remains unknown (Supplementary Figure S1 and Table S1), since there is a notorious lack of commercial standard compounds for Physalis genus [14].

Moreover, considering that sucrose esters are described as the main anti-inflammatory metabolites from the calyces of Physalis [15] and several anti-inflammatories withanolides have been isolated from P. angulata, we quantified the total content of sucrose esters [16] and withanolides [17] (Supplementary Methods). The results revealed that calyces from P. angulata are an important source of sucrose esters whereas the withanolides were at a low level (Supplementary Table S2). 


\subsection{PADF Modifies the Gene Expression Profile of Resting and LPS-Stimulated RAW 264.7 Macrophages} Promoting an Anti-Inflammatory Polarization

To gain insight into the effects of PADF on macrophages differentiation, RAW 264.7 cells were treated with the test fraction $(6.25$ and $12.5 \mu \mathrm{g} / \mathrm{mL})$ prior to polarization towards two contrasting activation states: inflammatory/LPS-activated [M(LPS)] and alternative/IL4-activated [M(IL4)]. As expected, inflammatory M(LPS) macrophages expressed higher mRNA levels of IL-1 $\beta$, tumor necrosis factor (TNF)- $\alpha$, IL-6, IL-12, cyclooxygenase (COX)-2, and inducible nitric oxide synthase (iNOS) (pro-inflammatory genes), as well as a strong reduction of arginase (ARG)1, IL-10, and mannose receptor $\mathrm{C}(\mathrm{MRC1})$ (anti-inflammatory genes) in comparison to the resting control (M0) (Figure 1A,B). In contrast, PADF significantly prevented the induction of pro-inflammatory genes, in a dose-dependent manner (Figure 1A). Additionally, the treatment with PADF significantly promoted the expression of anti-inflammatory genes (ARG1, IL-10, and MRC1) (Figure 1B).

Similarly, when evaluating these anti-inflammatory genes on M0 macrophages treated with PADF, a significant increase in the expression of ARG1, IL-10, TGF- $\beta 1$, and MRC1 mRNA was also observed (Figure 1C); suggesting that PADF might be capable of inducing a macrophage polarization shift towards an anti-inflammatory profile. However, the well-known expression of ARG1 or MRC1 by alternatively activated macrophages M(IL4) was not boosted by test fraction; moreover, no effects on IL-10 were observed (Figure 1D).

Finally, the $24 \mathrm{~h}$ accumulation of nitrite (marker of iNOS activity), urea (marker of ARG1 activity), and IL-10 (immunosuppressive cytokine) were measured using the Griess reaction [18], enzymatic detection or ELISA as detailed in Supplementary information. Results corroborated that PADF inhibited the production of nitrite by inflammatory M(LPS) macrophages, but did not increase the levels of urea in the case of alternative M(IL-4) macrophages (Supplementary Figure S3). However, when studying IL-10, the test fraction significantly inhibited its production by M(LPS) but had no effect in M(IL-4).

\subsection{P. angulata Fraction (PADF) Ameliorates DSS-Induced Colitis}

DSS intake produced a significant body weight decrease on the colitis-control group by the end of the last DSS cycle, while the administration of PADF at 5 and $10 \mathrm{mg} / \mathrm{Kg} / \mathrm{day}$ managed to reverse this disease sign with a full recovery of their body weight ( $0.95 \%$ and $0.62 \%$ weight gain, respectively) without reaching statistical significance. Moreover, disease activity index (DAI) score also tended to be diminished by PADF treatment (Figure 2A). A macroscopic evaluation was also performed in order to further assess the severity of the disease and the effect of the treatment, where colon length; a very common and important parameter in DSS-induced colitis, was measured. As can be seen in Figure 2B, both doses of PADF were able to significantly decrease the colon shortening when compared to the colitis-control group. The histologic analysis also showed that treatment with PADF (10 mg/Kg) produced a significant improvement in terms of edema, immune cell infiltration, and tissue structure integrity (Figure 2C) diminishing the histological score to $3.25 \pm 0.33$ in comparison to the colitis-control group $(5.17 \pm 0.33)$. 

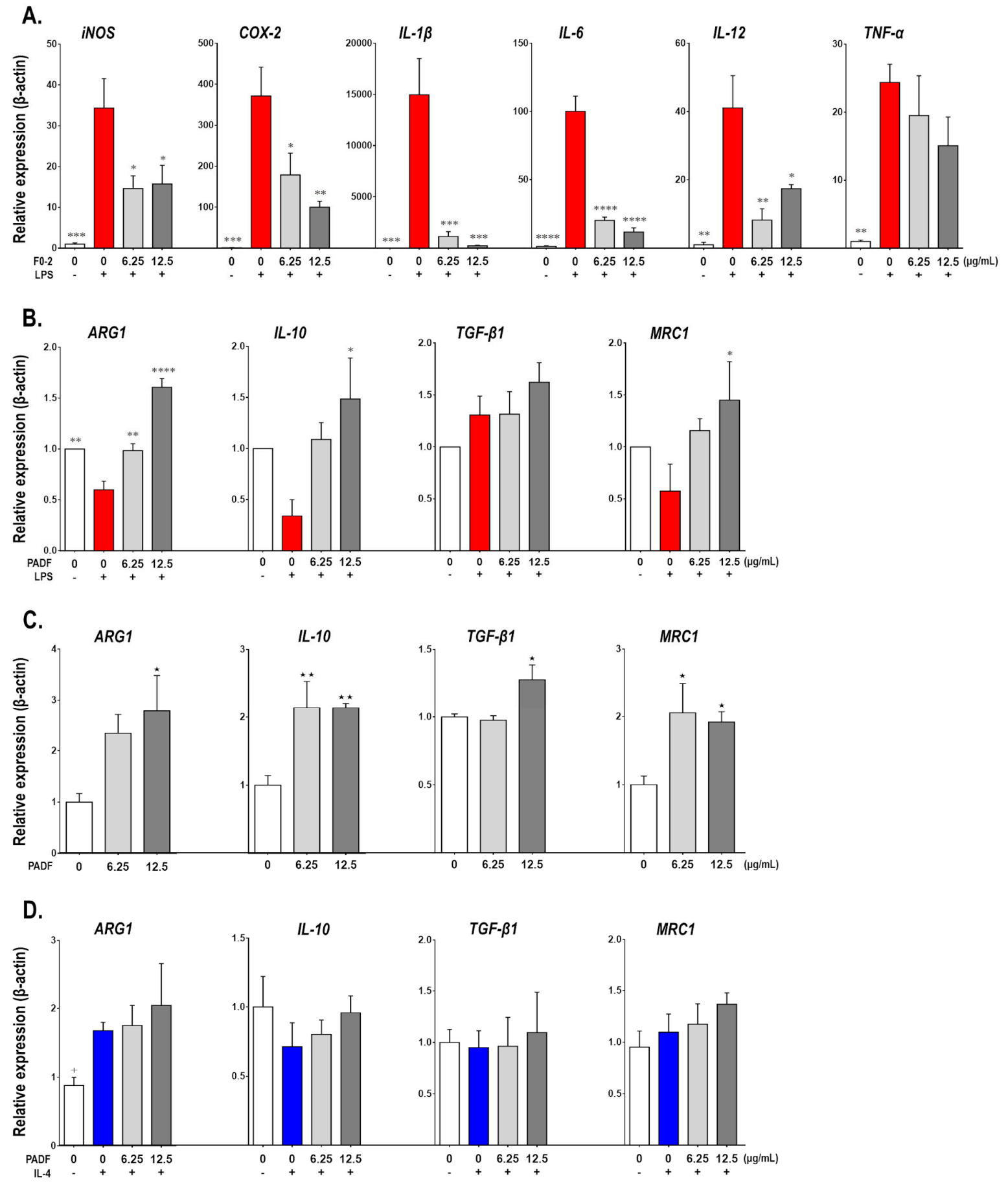

Figure 1. Physalis angulata fraction (PADF) polarizes macrophages towards an anti-inflammatory profile. Naïve RAW 264.7 macrophages were treated with PADF $(6.25$ and $12.50 \mu \mathrm{g} / \mathrm{mL}$ ) or vehicle (positive and negative controls) and then stimulated with LPS [M(LPS)] or IL-4 [M(IL4)]. The expression of pro-inflammatory gene markers was quantified for inflammatory M(LPS) macrophages (A); while the expression of anti-inflammatory markers was assessed for inflammatory M(LPS) (B), naïve (C), and alternatively M(IL-4) (D) macrophages. All graphs show the mean \pm SEM of at least three independent experiments $(n=4-9) .{ }^{*} p<0.05,{ }^{* *} p<0.01,{ }^{* * *} p<0.001,{ }^{* * *} p<0.0001$ significantly different from M(LPS) control; $+p<0.05$ significantly different from M(IL-4) control; or * $p<0.05,{ }^{* *} p<0.01$ significantly different from naïve control (ANOVA, Dunnett's multiple comparisons test). 
A. Body weight and Disease Severity
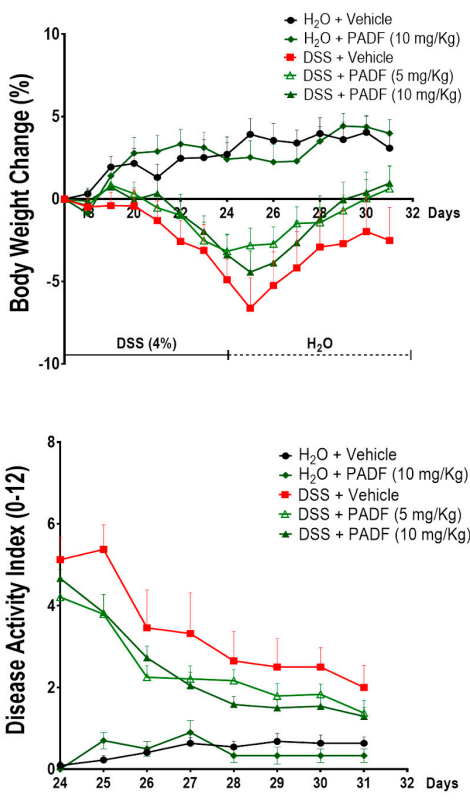

Figure 2. Chronic dextran sulfate sodium (DSS)-induced colitis is effectively treated by P. angulata fraction (PADF). Chronic colitis was established with two cycles of DSS (4\%) interrupted by normal drinking water. Affected mice ( $n=11-16$ per group) were treated with PADF (5 and $10 \mathrm{mg} / \mathrm{Kg} / \mathrm{day}$, ip) or vehicle (saline) for 7 days. PADF alleviated colitis promoting a trend of increased body weight and reduced disease activity index (DAI) by the end of the experiment (A). Moreover, PADF-treated mice showed significantly longer colons (B) and lower histological scores with marked reduction of epithelial damage and cell infiltration (C). Pictures from representative animals are shown. Results represent the mean $\pm \operatorname{SEM}(n=6-18)$ of three independent experiments. ${ }^{*} p<0.05,{ }^{* *} p<0.01$, ${ }_{* * * *} p<0.0001$ significantly different from DSS-colitis control, as calculated by ANOVA (Dunnett's multiple comparisons test).

Besides histologic analysis, polymorphonuclear cell infiltration can be indirectly determined by measuring the levels of myeloperoxidase (MPO) in the tissue. As shown on Figure 3A, DSS intake significantly increased the MPO activity in the colon $(91.60 \pm 11.00 \mathrm{U} / \mathrm{mg}$ protein) compared to the control group (52.44 $\pm 9.38 \mathrm{U} / \mathrm{mg}$ protein). In accordance with the observations on the histologic slides, treatment with PADF $(10 \mathrm{mg} / \mathrm{Kg}$ ) was able to significantly reduce the MPO activity by $44 \%$ approximately. Similarly, the lower dose of PADF $(5 \mathrm{mg} / \mathrm{Kg}$ ) exerted a significant reduction of MPO activity, confirming indirectly that the test fraction reduced the infiltration of pro-inflammatory cells.

Furthermore, the administration of PADF was associated with a diminished expression of pro-inflammatory cytokines and over-expression of anti-inflammatory cytokines. Indeed, mice treated with PADF showed reduced levels of IL-1 $\beta$ and TNF- $\alpha$, while levels of IL-10 were significantly increased. A non-significant decrease of IL-6 levels was also observed (Figure 3A).

Additionally, Figure 3B shows the effect of PADF on the production of IL-6 and MCP-1 by LPS-stimulated mesenteric lymph nodes (MLN) cells. The test fraction $(12.5 \mu \mathrm{g} / \mathrm{mL})$ did not affect the production of any of the soluble mediators on naïve cells. However, it significantly reduced the production of IL- 6 and MCP-1 by LPS-stimulated MLN cells. 
A.

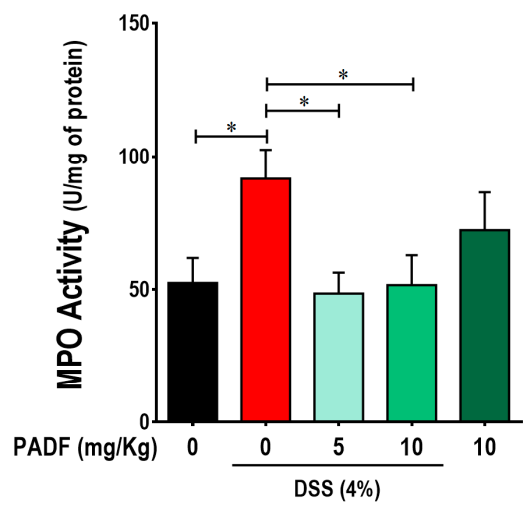

C. MLN cell culture supernatants

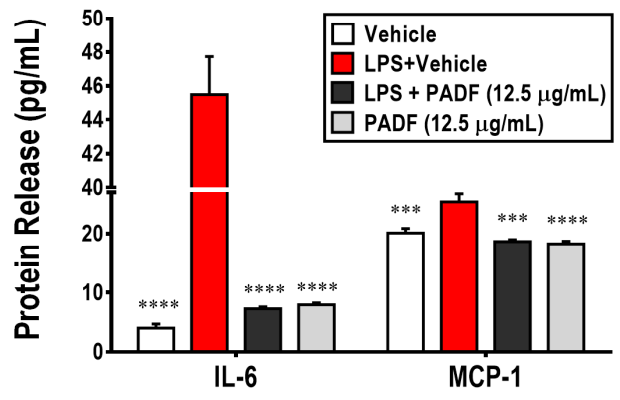

B.
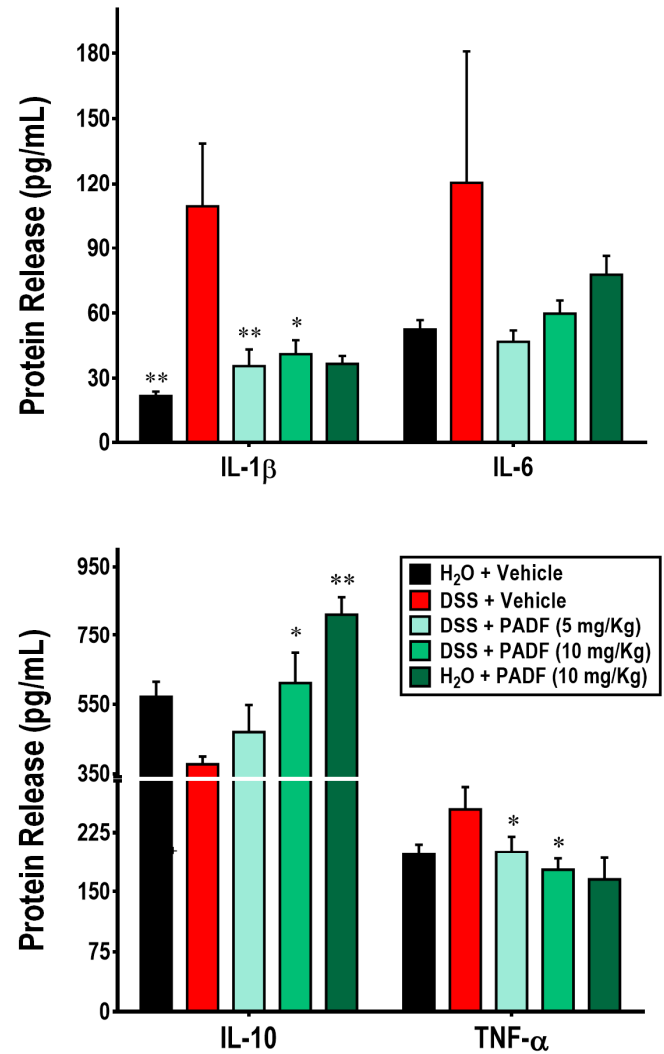

Figure 3. P. angulata fraction (PADF) exerts immunoregulatory effect in cells from colon and mesenteric lymph nodes (MLNs). The administration of PADF to mice with chronic colitis induced a significant reduction in the infiltration of neutrophils as demonstrated by a strong reduction of myeloperoxidase (MPO) activity (A). In addition, PADF regulated the levels of pro-inflammatory cytokines (IL-1 $\beta$ and TNF- $\alpha$ ), while significantly induced the production of IL-10, an anti-inflammatory cytokine (B). PADF also reduced the release of IL- $1 \beta$ and IL- 6 by MLN cells activated with LPS (C). Results represent the mean \pm SEM from at least two independent experiments $(n=6-16) .{ }^{*} p<0.05,{ }^{* *} p<0.01,{ }^{* * *} p<0.001$, $* * * * p<0.0001$ from DSS-colitis control group or LPS-activated MLN cells (ANOVA, Dunnett's multiple comparisons test).

\section{Discussion}

This study reveals the pharmacological potential of the dichloromethane fraction (PADF) of $P$. angulata calyces showing its capacity to ameliorate established DSS-colitis in mice. Our results suggest that PADF exerts its anti-inflammatory effect by inducing macrophage polarization towards a regulatory profile. In fact, PADF promotes a strong reduction of pro-inflammatory genes expression and a significant induction of anti-inflammatory markers, including IL-10, after stimulation with LPS or in resting macrophages. Moreover, a significant reduction of pro-inflammatory cytokines and the induction of IL-10 were observed in the colonic tissue of PADF-treated mice.

Physalis angulata is an annual herb that is distributed from North America (southeastern United States) to Central and South America (to Paraguay) and the Antilles [19]. In Colombia, this species grows from 0 to $1800 \mathrm{~m}$ above sea level and could be found throughout the country, where it constitutes one of the most common representatives of the Physalis genus. While the fruits are consumed by native indigenous communities, the aerial parts (including calyces) and fruits are commonly employed for its anti-inflammatory and anti-microbial properties [20]. So far, at least a dozen studies have demonstrated the ability of extracts, fractions, and compounds from $P$. angulata to inhibit inflammation and modulate the response of immune cells, including macrophages. To our knowledge, macrophages are the most commonly employed immune cells to study P. angulata derivatives, with all the reports employing 
LPS-stimulated macrophages [M(LPS)] and the quantification of pro-inflammatory mediators (such as NO, IL-6, and TNF- $\alpha$ ) to demonstrate their anti-inflammatory properties. However, with the exception of Rivera et al. [7], none of these reports focused on the calyces. Furthermore, no information is available regarding the impact of $P$. angulata on the expression of anti-inflammatory markers (i.e., IL-10 or TGF- $\beta 1$ ) by M(LPS) macrophages or the modulation of resting macrophages (M0) or alternatively activated macrophages [M(IL-4)]. Our study is the first to demonstrate that treatment with PADF modulated macrophage polarization towards a non-inflammatory phenotype. Specifically, PADF shifted the inflammatory status of M(LPS) with a potent reduction of iNOS, COX-2, IL-1 $\beta$, IL-6, and IL-12; that was accompanied by a significant increase of anti-inflammatory genes (ARG1, IL-10, MRC1, and TGF- $\beta$ ) which are poorly or not expressed by M0 or M(LPS) [21]. In all probability, this PADF-induced polarization does not promote the transition from the classically activated M(LPS) to the alternatively activated phenotype M(IL-4) since: (1) M0 treated with PADF not only expressed higher levels of alternative activation markers (i.e., ARG1 or MRC1), but also exhibited higher expression of anti-inflammatory genes (IL-10 and TGF- $\beta$ ); or (2) The treatment with PADF did not enhance the expression of alternative activation markers (i.e., ARG1 or MRC1) when stimulated with IL-4. In this case, results suggest that the phenotype promoted by PADF is similar to that induced by IL-10 [M(IL-10) or M2c] which is more related to the suppression of immune responses and tissue remodeling through the expression of markers, such as IL-10, TGF- $\beta$, and MRC1 [22].

As $P$. angulata is also employed in folk medicine to treat gastrointestinal discomfort [23], and considering the crucial role of macrophages in the pathogenesis and resolution of inflammatory bowel disease, we continued our study with the assessment of PADF using a therapeutic setting of DSS-induced colitis in mice. Results demonstrated that administration of PADF (10 mg/Kg/day) to mice with DSS chronic colitis significantly reversed the colon shortening, reduced the histological damage, neutrophil infiltration (as showed by MPO activity assay), and the production of inflammatory cytokines (IL-1 $\beta$ and TNF- $\alpha$ ). In addition, PADF induced the production of IL-10 in DSS-treated mice, a key immunoregulatory cytokine for the maintenance of intestinal homeostasis. In mice, macrophages are considered one of the most important sources of IL-10 to maintain and minimize mucosal immunopathology by promoting Foxp3 expression in regulatory $\mathrm{T}$ cells (Treg) and their function during colitis [24]. Hence, it is plausible that PADF significantly ameliorates DSS-colitis by means of macrophage transition towards an anti-inflammatory phenotype. This is reinforced by the decreased production of IL- 6 and MCP- 1 by activated MLN cells, mediators that also play a pivotal role in the migration and attraction of inflammatory macrophages to colonic tissue when damage is induced by DSS [25]. Further research is needed to undoubtedly demonstrate whether the effect of $P$. angulata is mediated by intestinal macrophages instead of other cell populations.

While this is not the first study describing the intestinal anti-inflammatory activity of P. angulata, since recently Almeida Junior et al. [26] demonstrated that a $\mathrm{CO}_{2}$ standardized extract from the aerial parts of the plant-PACO2-effectively prevented the colonic damage induced by TNBS in rats; this is the first report of the bioactivity of calyces from $P$. angulata in a model of colitis. Moreover, our results revealed their potential to treat, instead of preventing, established intestinal inflammation.

Another important result of the present study was the confirmation of significant amounts of glycosides and withanolides; secondary metabolites that might be responsible for the bioactivity, as previously reported by Rivera et al. [7]. Up to date, all the studies related to the anti-inflammatory activity of $P$. angulata were directed to the assessment of withanolides such as physalins, aromaphysalins, physangulatins, and whitangulatins, labdane-type diterpenoids, such as physangulatosides, or phenol glycosides, namely physanguloside A. Here we found that sucrose esters tended to be the more abundant class of compounds in PADF; therefore, it is likely that the pharmacological effects of this fraction are related to their presence. In accordance, they have been described as the major anti-inflammatory compounds from calyces, fruits, or the sticky coat of several Physalis species $[15,27,28]$.

Overall, we have identified PADF as a regulator of macrophage activation and inflammation. Our data suggest a potential therapeutic role of P. angulata in inflammatory bowel disease. 
Supplementary Materials: Supplementary materials can be found at http://www.mdpi.com/2227-9059/8/2/24/s1.

Author Contributions: Conceptualization, L.A.F. and Y.O.; Formal analysis, L.A.F., Y.O., and D.R.; Funding acquisition, L.A.F.; Investigation, Y.O. and D.R.; Methodology, L.A.F. and Y.O.; Project administration, L.A.F.; Resources, L.A.F.; Supervision, L.A.F.; Validation, Y.O. and D.R.; Writing-original draft, Y.O. and D.R.; Writing - review \& editing, L.A.F. All authors have read and agreed to the published version of the manuscript.

Funding: This research was funded by Colciencias and the University of Cartagena, grant numbers 110772553569 and 003-2015, respectively. Colciencias sponsored D.R. through the "Young Investigators and Innovators" program, grant number 548-2015.

Acknowledgments: The authors thank to Daneiva Caro for her assistance with animal care and handling.

Conflicts of Interest: The authors declare no conflict of interest. The funders had no role in the design of the study; in the collection, analyses, or interpretation of data; in the writing of the manuscript, or in the decision to publish the results.

\author{
Abbreviations \\ PADF Physalis angulata dichloromethane fraction \\ LPS Lipopolysaccharide \\ IL Interleukin \\ TNF- $\alpha$ Tumor Necrosis Factor $\alpha$ \\ COX-2 Cyclooxygenase-2 \\ iNOS Inducible nitric oxide synthase \\ ARG1 Arginase 1 \\ MRC1 Mannose receptor C type 1 \\ DSS Dextran Sodium Sulfate \\ DAI Disease Activity Index \\ MPO Myeloperoxidase \\ MLN Mesenteric Lymph Nodes
}

\title{
References
}

1. Tambo, E.; Khater, E.I.M.; Chen, J.-H.; Bergquist, R.; Zhou, X.-N. Nobel prize for the artemisinin and ivermectin discoveries: A great boost towards elimination of the global infectious diseases of poverty. Infect. Dis. Poverty 2015, 4, 58. [CrossRef]

2. WHO. WHO Traditional Medicine Strategy: 2014-2023; WHO Press: Hong Kong, China, 2013; pp. 1-76.

3. Newman, D.J.; Cragg, G.M. Natural Products as Sources of New Drugs from 1981 to 2014. J. Nat. Prod. 2016, 79, 629-661. [CrossRef]

4. Zhang, W.-N.; Tong, W.-Y. Chemical Constituents and Biological Activities of Plants from the Genus Physalis. Chem. Biodivers. 2016, 13, 48-65. [CrossRef]

5. Cicchetti, E.; Duroure, L.; Le Borgne, E.; Laville, R. Upregulation of Skin-Aging Biomarkers in Aged NHDF Cells by a Sucrose Ester Extract from the Agroindustrial Waste of Physalis peruviana Calyces. J. Nat. Prod. 2018, 81, 1946-1955. [CrossRef]

6. Li, A.-L.; Chen, B.-J.; Li, G.-H.; Zhou, M.-X.; Li, Y.-R.; Ren, D.-M.; Lou, H.-X.; Wang, X.-N.; Shen, T. Physalis alkekengi L. var. franchetii (Mast.) Makino: An ethnomedical, phytochemical and pharmacological review. J. Ethnopharmacol. 2018, 210, 260-274. [CrossRef]

7. Rivera, D.E.; Ocampo, Y.C.; Castro, J.P.; Barrios, L.; Diaz, F.; Franco, L.A. A screening of plants used in Colombian traditional medicine revealed the anti-inflammatory potential of Physalis angulata calyces. Saudi J. Biol. Sci. 2018. [CrossRef]

8. Morales Saavedra, J.d.C.; Rodríguez Zaragoza, F.A.; Cabrera Toledo, D.; Sánchez Hernández, C.V.; Vargas-Ponce, O. Agromorphological characterization of wild and weedy populations of Physalis angulata in Mexico. Sci. Hortic. 2019, 246, 86-94. [CrossRef]

9. Rengifo Salgado, E.; Vargas Arana, G. Physalis angulata L. (Bolsa Mullaca): Revisión de Usos Tradicionales, Química y Farmacología. Boletín Latinoamericano y del Caribe de Plantas Medicinales y Aromáticas 2013, 12, 5.

10. Kindscher, K.; Long, Q.; Corbett, S.; Bosnak, K.; Loring, H.; Cohen, M.; Timmermann, B.N. The Ethnobotany and Ethnopharmacology of Wild Tomatillos, Physalis longifolia Nutt., and Related Physalis Species: A Review. Econ. Bot. 2012, 66, 298-310. [CrossRef] 
11. Ding, N.; Wang, Y.; Dou, C.; Liu, F.; Guan, G.; Wei, K.; Yang, J.; Yang, M.; Tan, J.; Zeng, W.; et al. Physalin D regulates macrophage M1/M2 polarization via the STAT1/6 pathway. J. Cell. Physiol. 2019, 234, 8788-8796. [CrossRef]

12. Wirtz, S.; Neufert, C.; Weigmann, B.; Neurath, M.F. Chemically induced mouse models of intestinal inflammation. Nat. Protoc. 2007, 2, 541. [CrossRef]

13. Bradley, P.P.; Priebat, D.A.; Christensen, R.D.; Rothstein, G. Measurement of Cutaneous Inflammation: Estimation of Neutrophil Content with an Enzyme Marker. J. Investig. Dermatol. 1982, 78, 206-209. [CrossRef]

14. Zheng, Y.; Luan, L.; Chen, Y.; Ren, Y.; Wu, Y. Characterization of physalins and fingerprint analysis for the quality evaluation of Physalis alkekengi L. var. franchetii by ultra-performance liquid chromatography combined with diode array detection and electrospray ionization tandem mass spectrometry. J. Pharm. Biomed. Anal. 2012, 71, 54-62. [CrossRef]

15. Franco, L.A.; Ocampo, Y.C.; Gómez, H.A.; De la Puerta, R.; Espartero, J.L.; Ospina, L.F. Sucrose Esters from Physalis peruviana Calyces with Anti-Inflammatory Activity. Planta Med. 2014, 80, 1605-1614. [CrossRef]

16. Mima, H.; Kitamori, N. Chromatographic analysis of sucrose esters of long chain fatty acids. J. Am. Oil Chem. Soc. 1964, 41, 198-200. [CrossRef]

17. Devkar, S.T.; Suryapujary, S.M.; Jagtap, S.D.; Katyare, S.S.; Hegde, M.V. Effect of macronutrient deficiency on withanolides content in the roots of Withania somnifera and its correlationship with molybdenum content. Pharm. Biol. 2015, 53, 518-523. [CrossRef]

18. Green, L.C.; Wagner, D.A.; Glogowski, J.; Skipper, P.L.; Wishnok, J.S.; Tannenbaum, S.R. Analysis of nitrate, nitrite, and nitrate in biological fluids. Anal. Biochem. 1982, 126, 131-138. [CrossRef]

19. Vargas-Ponce, O.; Sánchez Martínez, J.; Zamora Tavares, M.d.P.; Valdivia Mares, L.E. Traditional management of a small-scale crop of Physalis angulata in Western Mexico. Genet. Resour. Crop. Evol. 2016, 63, 1383-1395. [CrossRef]

20. Ligarreto, G.A.; Lobo, M.; Correa, A. Recursos geneticos del genero Physalis en Colombia. In Avances en Cultivo, Poscosecha y Exportación de la Uchuva (Physalis peruviana L.) en Colombia; Fischer, G., Miranda, D., Piedrahita, W., Romero, J., Eds.; Universidad Nacional de Colombia: Bogota, Colombia, 2005; Volume 1, pp. 14-15.

21. Murray, P.J.; Allen, J.E.; Biswas, S.K.; Fisher, E.A.; Gilroy, D.W.; Goerdt, S.; Gordon, S.; Hamilton, J.A.; Ivashkiv, L.B.; Lawrence, T.; et al. Macrophage Activation and Polarization: Nomenclature and Experimental Guidelines. Immunity 2014, 41, 14-20. [CrossRef]

22. Mantovani, A.; Sica, A.; Sozzani, S.; Allavena, P.; Vecchi, A.; Locati, M. The chemokine system in diverse forms of macrophage activation and polarization. Trends Immunol. 2004, 25, 677-686. [CrossRef]

23. Lin, Y.-S.; Chiang, H.-C.; Kan, W.-S.; Hone, E.; Shih, S.-J.; Won, M.-H. Immunomodulatory Activity of Various Fractions Derived from Physalis angulata L Extract. Am. J. Chin. Med. 1992, 20, 233-243. [CrossRef]

24. Krause, P.; Morris, V.; Greenbaum, J.A.; Park, Y.; Bjoerheden, U.; Mikulski, Z.; Muffley, T.; Shui, J.-W.; Kim, G.; Cheroutre, $\mathrm{H}$.; et al. IL-10-producing intestinal macrophages prevent excessive antibacterial innate immunity by limiting IL-23 synthesis. Nat. Commun. 2015, 6, 7055. [CrossRef]

25. Perše, M.; Cerar, A. Dextran Sodium Sulphate Colitis Mouse Model: Traps and Tricks. J. Biomed. Biotechnol. 2012, 2012, 718617. [CrossRef]

26. Almeida Junior, L.D.; Quaglio, A.E.V.; de Almeida Costa, C.A.R.; Di Stasi, L.C. Intestinal anti-inflammatory activity of Ground Cherry (Physalis angulata L.) standardized CO2 phytopharmaceutical preparation. World J. Gastroenterol. 2017, 23, 4369-4380. [CrossRef]

27. Zhang, C.-R.; Khan, W.; Bakht, J.; Nair, M.G. New antiinflammatory sucrose esters in the natural sticky coating of tomatillo (Physalis philadelphica), an important culinary fruit. Food Chem. 2016, 196, 726-732. [CrossRef]

28. Pérez-Castorena, A.-L.; Martínez, M.; Maldonado, E. Labdanes and Sucrose Esters from Physalis sordida. J. Nat. Prod. 2010, 73, 1271-1276. [CrossRef]

(C) 2020 by the authors. Licensee MDPI, Basel, Switzerland. This article is an open access article distributed under the terms and conditions of the Creative Commons Attribution (CC BY) license (http://creativecommons.org/licenses/by/4.0/). 